\title{
Need for large scale randomised evidence about lowering LDL cholesterol in people with diabetes mellitus: MRC/BHF heart protection study and other major trials
}

Diabetes mellitus contributes substantially to the global burden of disease, with an estimated 100 million people affected worldwide, and its prevalence is increasing rapidly. ${ }^{1}$ Macrovascular complications are among the chief causes of major morbidity in people with diabetes, and most of their deaths are attributed to cardiovascular causes. ${ }^{2}{ }^{3}$ In type 2 ("non-insulin dependent") diabetes, blood triglyceride concentrations tend to be raised and high density lipoprotein (HDL) cholesterol concentrations reduced even with good metabolic control, whereas a similar pattern tends to emerge in type 1 ("insulin dependent") diabetes mellitus only when glycaemic control is poor. ${ }^{45}$ Typically in both type 1 and type 2 diabetes, however, blood concentrations of total and low density lipoprotein (LDL) cholesterol are similar to those in the general population. This may have contributed to the belief that LDL cholesterol is of little relevance to the risk of cardiovascular disease in diabetes ${ }^{46}$ and, apart from those with pronounced dyslipidaemia or pre-existing coronary heart disease (CHD), most people with diabetes do not receive cholesterol lowering treatment despite their increased risk.

Prospective epidemiological studies in the general population show that there is a positive association between CHD risk and blood total cholesterol concentration, which continues down at least to $3 \mathrm{mmol} / \mathrm{l}$ (that is, well below the range commonly seen in western populations $)^{7}$ without any evidence of a "threshold" below which lower cholesterol is not associated with lower risk. In these observational studies, the continuous association is roughly linear between CHD risk plotted on a doubling scale and the concentration of total or LDL cholesterol. This implies that the proportional reduction in CHD risk associated with a particular prolonged absolute difference in cholesterol is similar throughout the range studied. Hence, the absolute size of the reduction in CHD produced by lowering LDL cholesterol by a particular amount may be determined more by an individual's overall risk of CHD than by their initial cholesterol concentration. For example, among 360000 middle aged men in the USA screened for the multiple risk factor intervention trial (MRFIT), a prolonged $1 \mathrm{mmol} / \mathrm{l}$ lower blood total cholesterol was associated with about a $50 \%$ lower CHD risk, regardless of the baseline cholesterol concentration. ${ }^{8}$ Moreover, this association was of similar strength among the 5000 men in the study who had diabetes at baseline (which was presumed to be predominantly type 2) and among the remainder who did not, but the absolute risk of CHD death at each concentration of blood cholesterol was about 3-5 times higher in the presence of diabetes (fig 1). The United Kingdom prospective diabetes study (UKPDS) has provided further evidence of a similar direct, and continuous, association of CHD risk with LDL cholesterol concentration among about 3000 individuals with type 2 diabetes, and of an inverse association with HDL cholesterol concentration. ${ }^{9}$

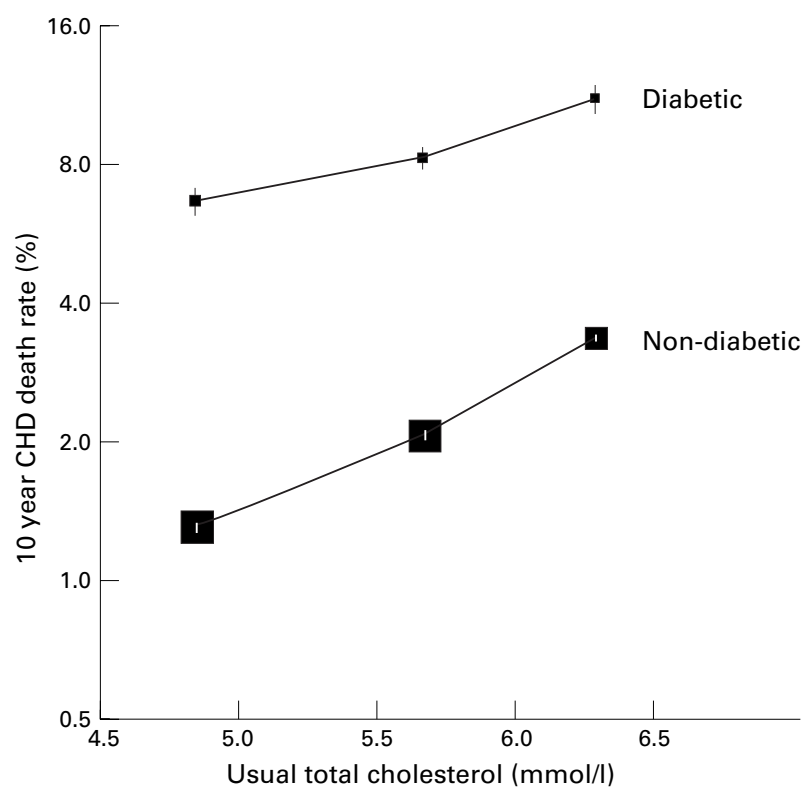

Figure 1 CHD risk versus usual total cholesterol in people with and without diabetes mellitus. MRFIT prospective follow up study of CHD death rates during an average of 16 years in 5245 men aged 35-57 years with diabetes mellitus and 350977 without diabetes ${ }^{8}(\mathcal{F}$ Neaton, personal communication). Death rates are plotted on a doubling scale, and "usual" cholesterol concentrations at the start of follow up have been derived from baseline measurements of cholesterol by correcting for "regression dilution". The area of each square is proportional to the statistical information with $\pm 1 S E$ denoted by a vertical line.

\section{Absolute benefits of lowering LDL cholesterol concentrations appear to depend chiefly on the absolute risks of coronary heart disease (rather than on cholesterol concentrations)}

Recently, large randomised trials have shown that lowering LDL cholesterol with HMG-CoA reductase inhibitors ("statins") reduces the risks of subsequent CHD mortality and morbidity in some types of high risk patient with preexisting CHD. ${ }^{10-12}$ The results of those trials indicated that, within just a few years of lowering blood cholesterol, CHD was reduced by about half as much as expected from a long term difference in cholesterol of the same magnitude. So, for example, a reduction of about $1 \mathrm{mmol} / 1$ in LDL cholesterol, maintained for 5-6 years, appeared to reduce the risk of CHD by about a quarter. A total of about 1500 of these patients with pre-existing CHD also had diabetes (predominantly type 2), and retrospective subgroup analyses suggested that the proportional effect on CHD risk among them was similar to that observed among the other patients studied (fig 2). ${ }^{12-14}$ Moreover, even though these trials tended to exclude patients at particular risk (for example, those with poorly controlled diabetes or raised triglyceride concentrations), the absolute risks of CHD were higher among the randomised patients with diabetes than among 


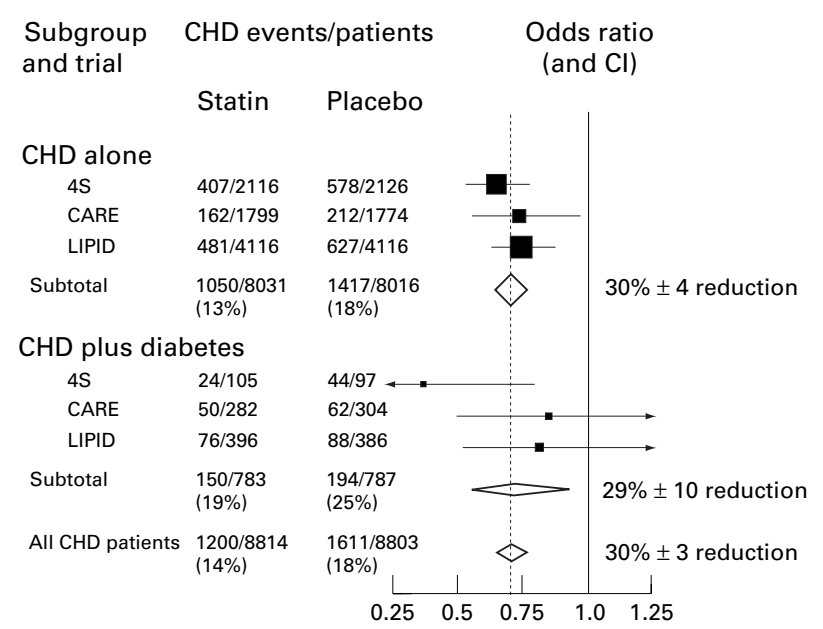

Figure 2 Observed effects on major CHD events in randomised controlled trials of cholesterol lowering with statin treatment among patients with pre-existing CHD, subdivided by diagnosed diabetes at entry. $4 S$ compared 20-40 mg daily simvastatin versus placebo, and the average difference in total cholesterol was $1.7 \mathrm{mmol} / \mathrm{l}^{10}{ }^{13} ; \mathrm{CARE}$ and LIPID compared $40 \mathrm{mg}$ daily pravastatin versus placebo, and the average differences in total cholesterol were 1.1 and 1.0 mmol/l, respectively. ${ }_{11} 1214$ Odds ratios for CHD events in each trial are plotted as black squares, with area proportional to the number of events, and $99 \%$ confidence intervals (CIs) are denoted by horizontal lines. Odds ratios and 95\% CI for subtotals and all CHD patients are plotted as open diamonds, with proportional reductions $( \pm S D)$ given alongside.

those without it-hence, their absolute benefits appeared to be larger.

These observations in the secondary prevention trials provide some indirect evidence that lowering LDL cholesterol may be worthwhile among people with diabetes who do not already have symptomatic CHD, but direct evidence that this is the case is not available. ${ }^{15}{ }^{16}$ Reliable assessment of a reduction in CHD risk of about a quarter or a third might well require trials involving at least a few hundred CHD events; however, the primary prevention trials of cholesterol lowering treatment completed so far have involved just a few CHD events among a few hundred patients with diabetes. ${ }^{17}{ }^{18}$ Hence, the Medical Research Council/British Heart Foundation (MRC/BHF) heart protection study was initiated in the early 1990s with the intention of recruiting a wide range of patients at increased risk of CHD, including a large cohort with diabetes, and maintaining a substantial LDL cholesterol difference for several years. ${ }^{19}$

\section{MRC/BHF heart protection study: a large trial of the effects on CHD of lowering LDL cholesterol in people with diabetes mellitus}

Between July 1994 and May 1997, 5963 people aged 40-80 years with diabetes mellitus were randomly entered into the heart protection study (along with a further 14573 high risk patients without diagnosed diabetes). ${ }^{19}$ Previous myocardial infarction was reported at study entry by 1125 $(19 \%)$ of these diabetic patients and some other history of CHD by a further 853 (14\%), but 3985 (67\%) had no history of CHD (and 2913 (49\%) had no history of any cardiovascular disease). According to predefined criteria, ${ }^{20}$ $615(10 \%)$ were classified as having type 1 diabetes and $5348(90 \%)$ as having type 2 diabetes (table 1). The patients with type 2 diabetes tended to be older than those with type 1 diabetes, to have more pre-existing CHD and hypertension, and to have higher non-fasting concentrations of blood total cholesterol, directly measured LDL cholesterol, apolipoprotein B and, particularly, triglycerides, and lower concentrations of HDL cholesterol, apolipoprotein $\mathrm{A}_{1}$, and $\mathrm{HbA}_{1 \mathrm{C}}$. Insulin was being used at study entry by $95 \%$ of patients with type 1 diabetes, whereas among those with type 2 diabetes insulin was being used by $25 \%$, sulfonylureas by $42 \%$, and metformin by $31 \%$.

Patients were randomly allocated to receive $40 \mathrm{mg}$ simvastatin daily, or matching placebo tablets, for at least five years (and, in a $2 \times 2$ factorial design, $600 \mathrm{mg}$ vitamin $\mathrm{E}$, $250 \mathrm{mg}$ vitamin $\mathrm{C}$, and $20 \mathrm{mg} \beta$ carotene daily, or matching placebo capsules). ${ }^{19}$ Based on random samples of the patients, it is estimated that LDL cholesterol concentrations at the four month follow up visit were below $3.0 \mathrm{mmol} / \mathrm{l}$ in $92 \%$ of simvastatin allocated versus $56 \%$ of placebo allocated diabetic patients without pre-existing CHD (compared to $91 \%$ v 35\% of all patients with pre-existing CHD). During 36 months of follow up, allocation to $40 \mathrm{mg}$ daily simvastatin has produced average reductions of $1.5 \mathrm{mmol} / 1$ in blood total cholesterol, $1.2 \mathrm{mmol} / 1$ in LDL cholesterol, and $0.4 \mathrm{mmol} / 1$ in triglycerides, with a small increase of $0.04 \mathrm{mmol} / 1$ in HDL cholesterol. The estimated annual incidence rate of non-fatal myocardial infarction plus fatal CHD among all 3985 diabetic patients without pre-existing CHD is about $1.5 \%$ (compared with about $2.5 \%$ among the non-diabetic patients with pre-existing CHD; the relative risk between these populations is smaller than that reported by some, ${ }^{21}$ but not all, ${ }^{22}$ small observational studies). Hence, by the end of the 5-6 year scheduled treatment period in 2001, the study may well be able to demonstrate an effect on CHD events of lowering LDL cholesterol in diabetic patients without a previous diagnosis of CHD (for example, $80 \%$ power to detect a reduction of a third at $\mathrm{p}<0.01$, table 2). Some information about the effects of cholesterol lowering on other vascular complications of diabetes may also emerge-for example, about 300 strokes and 200 amputations are expected among all of the patients with diabetes.

Table 1 Baseline characteristics of patients with diabetes mellitus in the $M R C / B H F$ heart protection study

\begin{tabular}{|c|c|c|c|}
\hline Characteristic at entry & Type $1(n=615)$ & \multicolumn{2}{|c|}{ Type $2(n=5348)$} \\
\hline \multicolumn{4}{|l|}{ Disease history } \\
\hline Myocardial infarction & $(5 \%)$ & 1095 & $(20 \%)$ \\
\hline Other CHD & $(5 \%)$ & 822 & $(15 \%)$ \\
\hline Other cardiovascular & $(20 \%)$ & 948 & $(18 \%)$ \\
\hline No cardiovascular & $(70 \%)$ & 2483 & $(46 \%)$ \\
\hline Treated hypertension & $(19 \%)$ & 2279 & $(43 \%)$ \\
\hline Duration of diabetes (years) & $28.6(0.5)$ & 9.3 & $(0.1)$ \\
\hline Age (years) & $52.6 \quad(0.3)$ & 63.2 & $(0.1)$ \\
\hline$\leqslant 65$ & $(92 \%)$ & 3082 & $(58 \%)$ \\
\hline$>65$ & $(8 \%)$ & 2266 & $(42 \%)$ \\
\hline Total cholesterol $(\mathrm{mmol} / \mathrm{l})$ & $5.52(0.04)$ & 5.68 & $(0.01)$ \\
\hline$\leqslant 5.5$ & $(51 \%)$ & 2464 & $(46 \%)$ \\
\hline$>5.5 \leqslant 7.0$ & $(42 \%)$ & 2349 & $(44 \%)$ \\
\hline$>7.0$ & $(7 \%)$ & 535 & $(10 \%)$ \\
\hline LDL cholesterol $(\mathrm{mmol} / \mathrm{l})^{\star}$ & $3.01(0.03)$ & 3.24 & $(0.01)$ \\
\hline$\leqslant 3.0$ & $(54 \%)$ & 2131 & $(40 \%)$ \\
\hline$>3.0 \leqslant 3.5$ & $(18 \%)$ & 1306 & $(24 \%)$ \\
\hline$>3.5$ & $(28 \%)$ & 1911 & $(36 \%)$ \\
\hline HDL cholesterol $(\mathrm{mmol} / \mathrm{l})^{\star}$ & $1.40(0.02)$ & 1.02 & $(0.00)$ \\
\hline$\leqslant 1.0$ & $96 \quad(16 \%)$ & 3023 & $(57 \%)$ \\
\hline$>1.0$ & $(84 \%)$ & 2325 & $(43 \%)$ \\
\hline Triglycerides (mmol/l) & $1.24(0.03)$ & 2.38 & $(0.02)$ \\
\hline$\leqslant 2.0$ & $526 \quad(86 \%)$ & 2690 & $(50 \%)$ \\
\hline$>2.0$ & $(14 \%)$ & 2658 & $(50 \%)$ \\
\hline $\mathrm{HbA}_{1 \mathrm{c}}(\%)+$ & $7.90(0.09)$ & 7.04 & $(0.03)$ \\
\hline$\leqslant 7.0$ & $235 \quad(38 \%)$ & 3025 & $(57 \%)$ \\
\hline$>7.0$ & $(62 \%)$ & 2318 & $(43 \%)$ \\
\hline
\end{tabular}

Values are either $\mathrm{n}(\%)$ or mean (SE).

*Corresponding differences between those with type 1 and type 2 diabetes were seen in blood concentrations of apolipoprotein B (1.01 (0.01) g/l v $1.11(0.003)$ $\mathrm{g} / \mathrm{l})$ and of apolipoprotein $\mathrm{A}_{1}(1.33(0.01) \mathrm{g} / \mathrm{l} v 1.18(0.003) \mathrm{g} / \mathrm{l})$.

$+\mathrm{HbA}_{1 \mathrm{C}}$ was measured by a turbidimetric method on Beckman Synchron CX autoanalysers (manufacturer's normal range $2.9-4.6 \%$ ). 
Table 2 Major trials of the effects of lowering $L D L$ cholesterol among diabetic patients without pre-existing $C H D^{\dagger}$

\begin{tabular}{|c|c|c|c|c|}
\hline Trial $^{*}$ & Type of diabetic patient & Cholesterol lowering treatment comparison & $\begin{array}{l}\text { Approx number of } C H D \\
\text { events/diabetic patients } \\
\text { without pre-existing } \\
C H D\end{array}$ & $\begin{array}{l}\text { Scheduled } \\
\text { end date }\end{array}$ \\
\hline HPS & Type 1 and 2 (see table 1$)$ & Simvastatin $40 \mathrm{mg}$ daily $v$ placebo & $300 / 4000$ & 2001 \\
\hline ALLHAT & Type 2 with hypertension & Pravastatin $40 \mathrm{mg}$ daily $v$ usual care & $250 / 3500$ & 2002 \\
\hline ASPEN & Type 2 with one risk factor & Atorvastatin $10 \mathrm{mg}$ daily $v$ placebo & $300 / 2000$ & 2003 \\
\hline CARDS & Type 2 with one risk factor & Atorvastatin $10 \mathrm{mg}$ daily $v$ placebo & $300 / 3000$ & 2004 \\
\hline ASCOT & $\begin{array}{l}\text { Type } 2 \text { with hypertension } \\
\text { and two other risk factors }\end{array}$ & Atorvastatin $10 \mathrm{mg}$ daily $v$ placebo & $200 / 4000$ & 2004 \\
\hline LDS & Type 2 & $\begin{array}{l}\text { Cerivastatin } 0.4 \mathrm{mg} \text { daily } v \text { placebo } \\
\text { (and, in factorial design, fenofibrate } v \text { placebo) }\end{array}$ & $450 / 5000$ & 2005 \\
\hline
\end{tabular}

${ }^{\star}$ See box for explanation of trial acronyms.

${ }^{\dagger}$ Trials with at least $100 \mathrm{CHD}$ events expected during about 5 years of $\geqslant 1.0 \mathrm{mmol} / \mathrm{l}$ difference in LDL cholesterol.

\section{Other large trials of lowering LDL cholesterol in patients with diabetes mellitus}

Several other cholesterol lowering trials are in progress among diabetic patients without previously diagnosed CHD, but these involve much smaller LDL cholesterol reductions (as, for example, in the low fat diet comparison of the women's health initiative ${ }^{23}$ or in the FIELD trial of fenofibrate), fewer CHD events, and/or more recent recruitment than the MRC/BHF heart protection study. Table 2 summarises those trials that are intended to involve reductions in LDL cholesterol of at least $1 \mathrm{mmol} / 1$ and at least $100 \mathrm{CHD}$ events among such patients. ${ }^{19} 2425$ Statins are particularly effective at lowering LDL cholesterol concentrations, whereas fibrates are more effective at lowering triglycerides. ${ }^{26}$ But, although the combination of a statin and a fibrate might be particularly effective, these drugs have not typically been used together because of concerns that the risks of myopathy might be increased. ${ }^{15}{ }^{16}$ By using a factorial design, the lipids in diabetes study (LDS) should allow the more reliable assessment of the beneficial or adverse effects of combining these treatments.

\section{Conclusion: eventual emergence of clear evidence about the effects of lowering LDL cholesterol concentrations in people with diabetes mellitus}

There is good epidemiological evidence of continuous direct associations between cardiovascular disease risk and both blood pressure levels ${ }^{27}$ and LDL cholesterol concentrations ${ }^{78}$ throughout the ranges studied in different populations. Hence, lower levels of these risk factors might well-at least in the long term-be associated with lower levels of cardiovascular risk in people with diabetes. ${ }^{15} 16$ The UKPDS randomised trial has indicated that lowering blood pressure in type 2 diabetes reduces the risk of major cardiovascular complications, ${ }^{28}$ and a retrospective combined analysis of secondary prevention trials of LDL cholesterol lowering with statins found similar proportional risk reductions among the relatively small numbers of diabetic patients studied and among the other patients with pre-existing CHD. ${ }^{12-14}$ The MRC/BHF heart protection study should provide the first large scale prospective evidence as to whether reducing LDL cholesterol concentrations in a wide range of diabetic patients produces worthwhile benefits (without any counterbalancing adverse consequences). But really reliable evidence about the effects of cholesterol lowering on cause specific mortality and morbidity in people with diabetes is only likely to emerge from the prospectively planned cholesterol treatment trialists' collaborative meta-analysis of the results of all relevant randomised trials. ${ }^{29}$

\section{Trial acronyms \\ ALLHAT: Antihypertensive and Lipid Lowering treat- ment to prevent Heart Attack Trial \\ ASCOT: Anglo-Scandinavian Cardiac Outcomes Trial \\ ASPEN: Atorvastatin Study for the Prevention of End- points in NIDDM \\ CARDS: Collaborative Atorvastatin in Diabetes Study \\ CARE: Cholesterol And Recurrent Events \\ FIELD: Fenofibrate Intervention and Event Lowering in Diabetes \\ HPS: Heart Protection Study \\ LDS: Lipids in Diabetes Study \\ LIPID: Long-term Intervention with Pravastatin in Ischaemic Disease \\ MRFIT: Multiple Risk Factor Intervention Trial \\ 4S: Scandinavian Simvastatin Survival Study \\ UKPDS: United Kingdom Prospective Diabetes Study}

The most important acknowledgement is to the patients participating in the MRC/BHF heart protection study (as well as those in the other studies), and to the collaborators in that study listed in reference 19 . The MRC/BHF heart protection study is being funded by the UK Medical Research Council, the British Heart Foundation, Merck Sharp \& Dohme (manufacturers of simvastatin), and Hoffmann-La Roche (manufacturers of the vitamins). It was, however, designed Hoffmann-La Roche (manufacturers of the vitamins). It was, however, designed
independently of the pharmaceutical companies, who have no representative in its organisation and who, like the steering committee and investigators, remain blind to the main results as they accumulate.

JANE ARMITAGE RORY COLLINS

MRC/BHF Heart Protection Study,

Clinical Trial Service Unit and Epidemiological Studies Unit,

Nuffield Department of Clinical Medicine,

Radcliffe Infirmary,

Oxford OX2 6HE, UK

1 Amos AF, McCarty DJ, Zimmet P. The rising global burden of diabetes and its complications: estimates and projections to the year 2010. Diabetic Med 1997;14(suppl 5):S1-85

2 Garcia MJ, McNamara PM, Gordon T, et al. Morbidity and mortality in diabetics in the Framingham population. Sixteen year follow-up study. Diabetes 1974;23:105-11.

3 Panzram G. Mortality and survival in type 2 (non-insulin-dependent) diabetes mellitus. Diabetologia 1987;30:123-31.

4 Pyörälä K, Laakso M, Uusitupa M. Diabetes and atherosclerosis: an epidemiologic view. Diabetes/Metabolism Reviews 1987;3:463-524.

miologic view. Diabetes/Metabolism Reviews 1987;3:463-524.
5 UK Prospective Diabetes Study Group. UK prospective diabetes study 27. UK Prospective Diabetes Study Group. UK prospective diabetes study 27.
Plasma lipids and lipoproteins at diagnosis of NIDDM by age and sex. DiaPlasma lipids and lipoprote
bet Care 1997;20:1683-7.

6 Grundy SM, Benjamin IJ, Burke GL, et al. Diabetes and cardiovascular disease. A statement for healthcare professionals from the American Heart Association. Circulation 1999;100:1134-46.

7 Jacobs D, Blackburn H, Higgins M, et al. Report of the conference on low blood cholesterol: mortality associations. Circulation 1992;86:1046-60.

8 Stamler J, Vaccaro O, Neaton JD, et al for the Multiple Risk Factor Intervention Trial Research Group. Diabetes, other risk factors and 12-year cardiovascular mortality for men screened in the multiple risk factor intervention trial. Diabetes Care 1993;16:434-44.

9 Turner RC, Millns H, Neil HAW, et al for the United Kingdom Prospective Diabetes Study Group. Risk factors for coronary artery disease in non-insulin dependent diabetes mellitus: United Kingdom prospective non-insulin dependent diabetes mellitus: United Kingdom prospective
diabetes study (UKPDS: 23). BMF 1998;316:823-8.

10 Scandinavian Simvastatin Survival Study Group. Randomised trial of cholesterol lowering in 4444 patients with coronary heart disease: the esterol lowering in 4444 patients with coronary heart disease: the
Scandinavian simvastatin survival study (4S). Lancet 1994;344:1383-9.

11 Sacks FM, Pfeffer MA, Moyé LA, et al for the Cholesterol and Recurrent Events Trial Investigators. The effects of pravastatin on coronary events 
fter myocardial infarction in patients with average cholesterol levels. $N$ Engl 7 Med 1996;335:1001-9.

12 The Long-term Intervention with Pravastatin in Ischaemic Disease (LIPID) Study Group. Prevention of cardiovascular events and death with pravastatin in patients with coronary heart disease and a broad range of initial cholesterol levels. N Engl F Med 1998;339:1349-57.

13 Pyörälä K, Pedersen TR, Kjekshus J, et al for the Scandinavian Simvastatin Survival Study (4S) Group. Cholesterol lowering with simvastatin improves prognosis of diabetic patients with coronary heart disease. Diabetes Care 1997;20:614-20.

14 Goldberg RB, Mellies MJ, Sacks FM, et al for the CARE Investigators. Cardiovascular events and their reduction with pravastatin in diabetic and glucose-intolerant myocardial infarction survivors with average cholesterol levels. Subgroup analyses in the cholesterol and recurrent events (CARE) trial. Circulation 1998;98:2513-19.

15 Haffner SM. Management of dyslipidemia in adults with diabetes. Diabetes Care 1998;21:160-78.

16 American Diabetes Association. Management of dyslipidemia in adults with diabetes. Diabetes Care 1998;21:179-82.

17 Shepherd J, Cobbe SM, Ford I, et al for the West of Scotland Coronary Prevention Study Group. Prevention of coronary heart disease with pravastatin in men with hypercholesterolemia. N Engl f Med 1995;333:1301-7.

18 Downs JR, Clearfield M, Weis S, et al for the AFCAPS/TexCAPS Research Group. Primary prevention of acute coronary events with lovastatin in men and women with average cholesterol levels. Results of AFCAPS/TexCAPS. fAMA 1998;279:1615-22.

19 MRC/BHF Heart Protection Study Collaborative Group. MRC/BHF heart protection study of cholesterol-lowering therapy and of antioxidant vitamin supplementation in a wide range of patients at increased risk of coronary heart disease death: early safety and efficacy experience. Eur Heart f 1999; 20:725-41.
20 Prior MJ, Prout T, Miller D, et al and the ETDRS Research Group. C-peptide and the classification of diabetes mellitus patients in the early treatment diabetic retinopathy study. Report number 6. Ann Epidemiol 1993;3:9-17.

21 Haffner SM, Lehto S, Rönnemaa T, et al. Mortality from coronary heart disease in subjects with type 2 diabetes and in nondiabetic subjects with and without prior myocardial infarction. N Engl f Med 1998:339:229-34.

22 Simons LA, Simons J. Diabetes and coronary heart disease. $N$ Engl $7 \mathrm{Med}$ 1998:339:1714-15.

23 The Women's Health Initiative Study Group. Design of the women's health initiative clinical trial and observational study. Control Clin Trials 1998;19: 61-109.

24 Davis BR, Cutler JA, Gordon DJ, et al. Rationale and design for the antihypertensive and lipid lowering treatment to prevent heart attack trial (ALLHAT). Am 7 Hypertens 1996;9:342-60.

25 Dahlof B, Sever PS, Poulter NR, et al. The Anglo-Scandinavian cardiac outcomes trial (ASCOT). F Hypertens 1998;16(suppl 2): P27.092.

26 Shepherd J. Fibrates and statins in the treatment of hyperlipidaemia: an appraisal of their efficacy and safety. Eur Heart $\mathcal{F} 1995 ; 16: 5-13$

27 MacMahon S, Peto R, Cutler J, et al. Blood pressure, stroke and coronary heart disease. Part 1, prolonged differences in blood pressure: prospective observational studies corrected for the regression dilution bias. Lancet 1990;335:765-74.

28 UK Prospective Diabetes Study Group. Tight blood pressure control and risk of macrovascular and microvascular complications in type 2 diabetes: UKPDS 38. BM7 1998;317:703-13.

29 Cholesterol Treatment Trialists' (CTT) Collaboration. Protocol for a prospective collaborative overview of all current and planned randomized trials of cholesterol treatment regimens. Am f Cardiol 1995;75:1130-4.

\section{STAMPS IN CARDIOLOGY}

\section{Congresses}

Mandrake, Mandragora officinarum, has hyoscine (scopolamine), an antimuscarinic drug, in its root. Hyoscine is a narcotic and it is remarkable that its use for premedication before surgery has not changed for 2000 years. The herbalist Dioscorides in $\mathrm{AD} 100$ gave mandrake so that "such as shall be cut or cauterised are overborne with deep sleep" and to day hyoscine may still be used before anaesthesia and surgery. Hyoscine, unlike atropine, produces only a slight tachycardia and is not used in cardiac treatment. But in a very low dose hyoscine produces a paradoxical increase in cardiac vagal activity, and this action has been utilised to study baroreflex sensitivity in patients with heart failure (Heart 1996;75:274-80).

In ancient times mandrake was a highly prized medicinal plant, and professional herb gatherers invented a legend to deter others from harvesting it. It was said that when a man dug up a mandrake it gave a terrible shriek which killed him. But this problem was solved by using a dog (which died) to pull the plant out of the ground while the man stopped his ears. This is well shown in the old herbal illustration on the stamp. The forked root of the plant was said to resemble a human being, hence the name mandrake.

Mandrake belongs to the family Solanaceae, which contains species with the pharmacologically important drugs atropine and nicotine. Other plants in the family include potato, tomato, and pepper (capsicum).

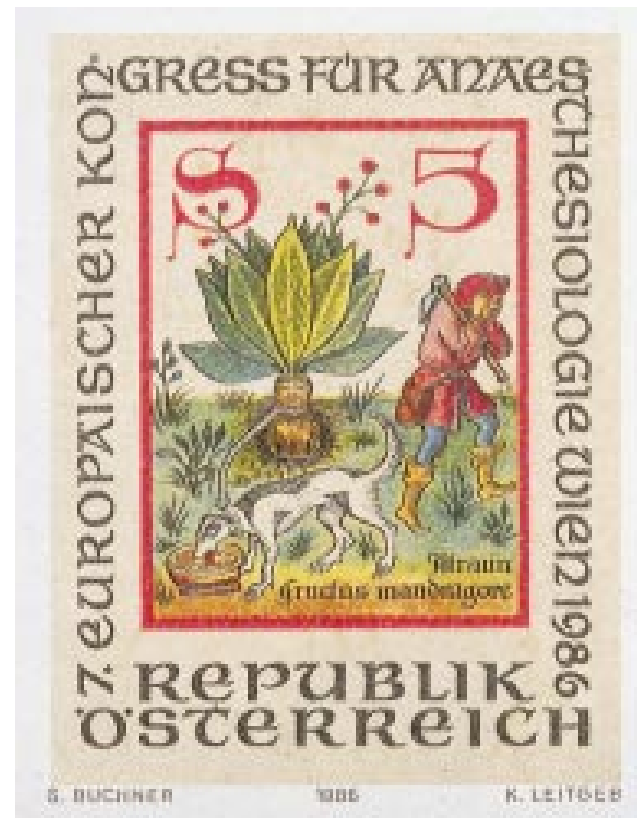

The 5 schilling Austrian stamp depicting man collecting mandragora (from Codex Tacuinum Sanitatis) was a single denomination issue from 1986 to commemorate the 7th European Anaesthesia Congress held in Vienna.

M K DAVIES A HOLLMAN 